\title{
To Be or Not To Be an Engineer: Towards Globalizing Malaysia.
}

\author{
Yu Jin Ng ${ }^{1}$, Seng Tong Chong ${ }^{1}$, Noor Azam Bin Abdul Rahman ${ }^{1}$, Mohd Ariff Ahmad Tarmizi ${ }^{1}$ \\ \& Shameem Rafik-Galea ${ }^{2}$ \\ ${ }^{1}$ Universiti Tenaga Nasional, ${ }^{2}$ University Putra Malaysia
}

\begin{abstract}
The recent Malaysian Education Blueprint (2013-2025) indicates that one of the main targeted shifts is to fortify and strengthen the necessary fundamentals in the field of engineering. Hence, identifying the right talent with suitable personality and capability is critical and essential. The right talent will be able to ensure a brighter tomorrow and help in developing our Malaysia. Therefore, at the heart of this study is an attempt to reconceive the idea and ideal "engineer" within the frame of a holistic education analysis and in the light of contemporary concerns and demands. It attends closely to the characteristics of an 'engineer" indicating the needs which resonate with that of contemporary market for an "engineer" in terms of intelligence, personality, technical language and knowledge. This software provides a platform for the respondent to assess his or which is deemed essential for becoming an engineer. This software acts as a repository for data storage which includes the digitized credentials and matches the need of the industry. This is an increasingly substantial from in ensuring Malaysia at the competitive arena of the future economy of the world.
\end{abstract}

Keywords: Engineering Aptitude Test, Engineering Intelligence, Engineering Personality, Engineering Technical Language.

\section{Introduction}

"Career development, for most people, is a lifelong process of engaging the work world through choosing among employment opportunities made available to them" (Ferry, 2006, p.1). Career development is influenced by many factors, which include demographic factor, personal aptitudes, and educational attainment (Bandura, Barbaranelli, Caprara, \& Pastorelli, 2001). Thoresen and Ewart (1976) strongly advocate that self-managed change behavioural self-control is the key to focused career selection. Selfcontrol in this study refers to the scope or extent one understand self just as what Gardner (1983) termed as 'intrapersonal' intelligence. "Self-control is viewed here as a series of specific, cognitively mediated actions that a person uses to regulate and alter situations, including the cognitive environment, so that desired change takes place" (Thoresen \& Ewart, 1976).

The higher understanding of self, the higher the self-control would measure up (Thoresen, Kirmil-Gray \& Crobie, 1978). According to Lieberman (2010, p.111), "regardless the opportunities in life, a lack of selfcontrol would result in poor choices made in life and ultimately lead to negative or destructive output or habits". Lieberman's (2010) notion is that making certain decision actually affects one's progression or regression in life, especially career in this context. The ability to make decision is always influenced by experience and logical understanding of things.

Self-control is believed to be one of the main factors to making good decision in life (Thoresen, KirmilGray \& Crobie, 1978). Lieberman (2010) explains that with high self-control, one will have high self esteem in which it deflates egoism in self. Thus, with low ego in oneself, it gives broader perspectives of life to one and it reaffirms one's stand or self-control in whatever that one pursues. High self-control in the form of reaffirmation boosts self-belief and confidence in any undertakings. According to Lieberman (2010), the diagram below is a 'closed loop' and the main factor to determine if one can progress or even regress in life lies in the ability to understand self, defining one's self-control which in turn determines one's career development. Figure 1 summarizes the thoughts put forward by Lieberman (2010). 


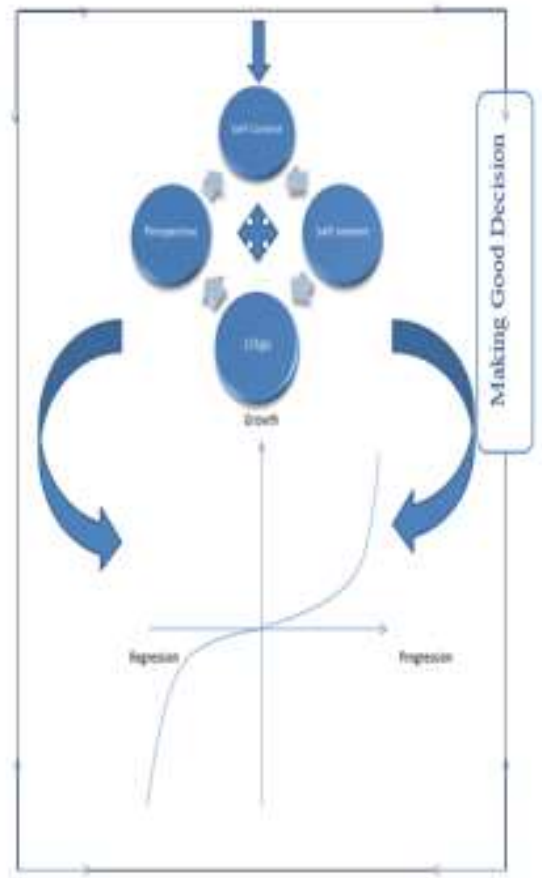

Fig. 1: Factors influencing decision making (Lieberman, 2010)

The need for specialised skills and talent in every field is inevitable due to the technological progress. Also, the search for niche talent in any discipline has always been a quest, especially in the field of engineering. According to the Ministry of Education Malaysia (2012), in Malaysian Education Blueprint (2013-2025), one of the main targeted shifts is to fortify and strengthen the necessary fundamentals in the field of engineering. Identifying the right talents and ensuring that they possess adequate engineering skills and knowledge is undoubtedly essential to realizing the education blueprint as well as transforming the phase of industrial and technological development of the nation.

In ensuring students making good decision in terms of career choice especially engineering, this study focuses on the personal aptitude factor to determine if one is suitable to be an engineer by profession. It incorporates the personality, intelligence and technical vocabulary knowledge aptitude test to determine if one is ready or in control in terms of self-investment and development. The personality test for engineers is adapted from the validated multiple intelligences tests proposed by Gardner (1983). Only intelligences which relate to engineering characteristics were used in the engineering aptitude test. In addition, the personality test used was adapted from Jung's (1971) and Myers and Myers's (1995) framework. The questions were customized to suit to the current context. The final tests were created by the researchers to test the students' technical vocabulary skills.

Thus, this study aims to develop an assessment tool to holistically determine the extent a respondent is suitable to be an engineer. This software provides a platform for the respondent to assess his or her intelligence, personality, technical language and knowledge which is deemed essential for becoming an engineer. It is important to match the respondents to the most relevant engineering job made available to them as well as assisting companies to select the most desirable talent in fulfilling the mission of the company. This software stores the data of the respondents with their respective digitized credentials and matches the need of the industry. The framework of this prototype software is summarized as below (Fig.2). With the software, it is aimed to assist students in making good decision, enhancing their self-control in choosing engineering as their desired profession. 


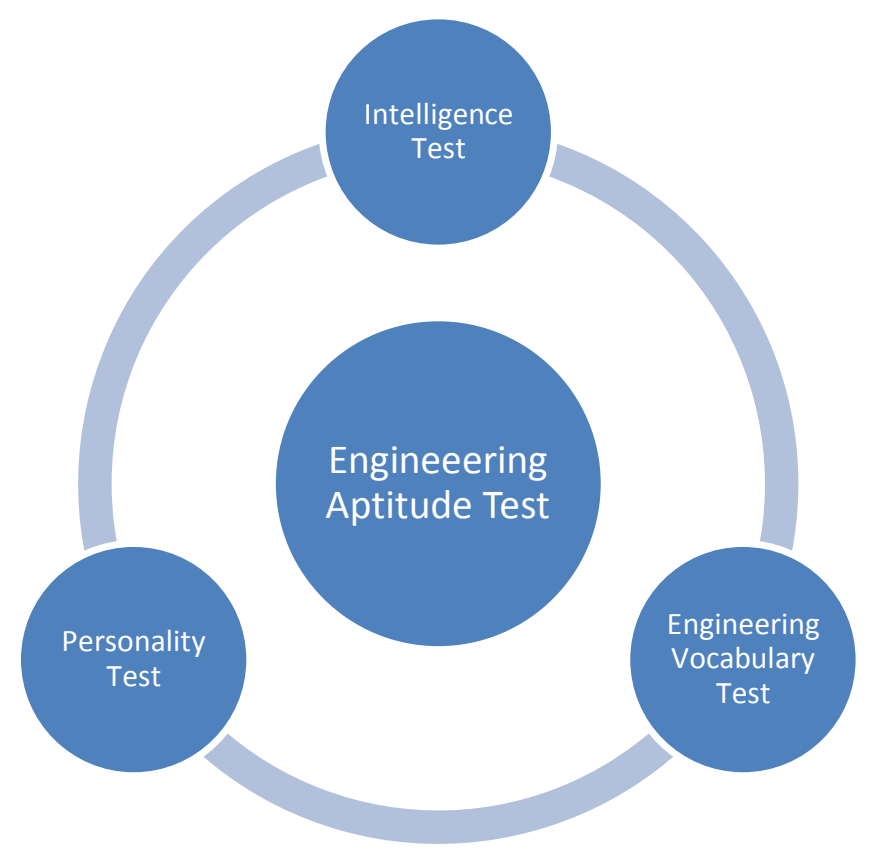

Fig. 2: Framework of the Prototype Software

\section{Specialised Engineering Vocabulary Tool in the Prototype Software}

At present, the English language command of graduate student engineers can be evaluated through the certifications, proficiency test results or even diagnostic tests provided by job-matching agencies. In addition, a potential engineer's proficiency in English is assessed during the job interviews as well to ensure the engineers they hire can speak the lingua franca of the world proficiently. However, there is no an instrument that gauge or evaluate a potential engineer's technical vocabulary in any given engineering fields which is essential in reading manuals for engineering application purposes.

Engineers need the technical or specialised engineering vocabulary for further professional development, especially associating them to their discourse community (Coxhead, 2013; Nesi, 2013). Impressionistic or random questioning of the engineering knowledge or vocabulary is not sufficed to ensure a quality employee is being hired. In the engineering discourse community, an engineer needs the technical or specialised language to function at the optimum level (Mukundan \& Ng, 2012; Ng et al., 2013; Alif Fairus Nor Mohamad \& Ng, 2013; Hsu, 2014).

Adopting the concept and framework advocated by Nation (2006) and Nation and Beglar (2007), a reliable instrument of evaluation on the technical vocabulary can be created. Using the sophistication and processes in corpus linguistics (see $\mathrm{Ng}$ et al., 2013), the technical vocabulary list can be developed which in turn transformed into a holistic technical vocabulary assessment. The users this tool, especially engineering companies can now evaluate their candidates to distinguish the more specialised one. In terms of economy, users saved time when evaluating the candidates as everything can be autonomous. Engineering students too can benefit from this tool by assessing personal specialised knowledge and find out specifically what more they should learn or improve on.

\section{Results and Discussion: The functions (interface) of the prototype software}

This study has developed an assessment tool to holistically determine the extent a respondent is suitable to be an engineer. This software provides a platform for the respondent to assess his or her intelligence, personality, technical language and knowledge which is deemed essential for becoming an engineer. Becoming an engineer should be by choice and the choice itself should be a good decision for the respondent. It would then match the respondent's forte and aptitude with the vast available engineering jobs posted by potential employers or even by universities for those who yet to obtain their academic qualifications. 
The detailed description of the software is discussed as below:

Respondents register and their personal details (as shown in Fig.3), together with their personality and intelligence aptitude test (PIAT) results will be stored in the database. It is designed to match the criteria set by any concerning parties.

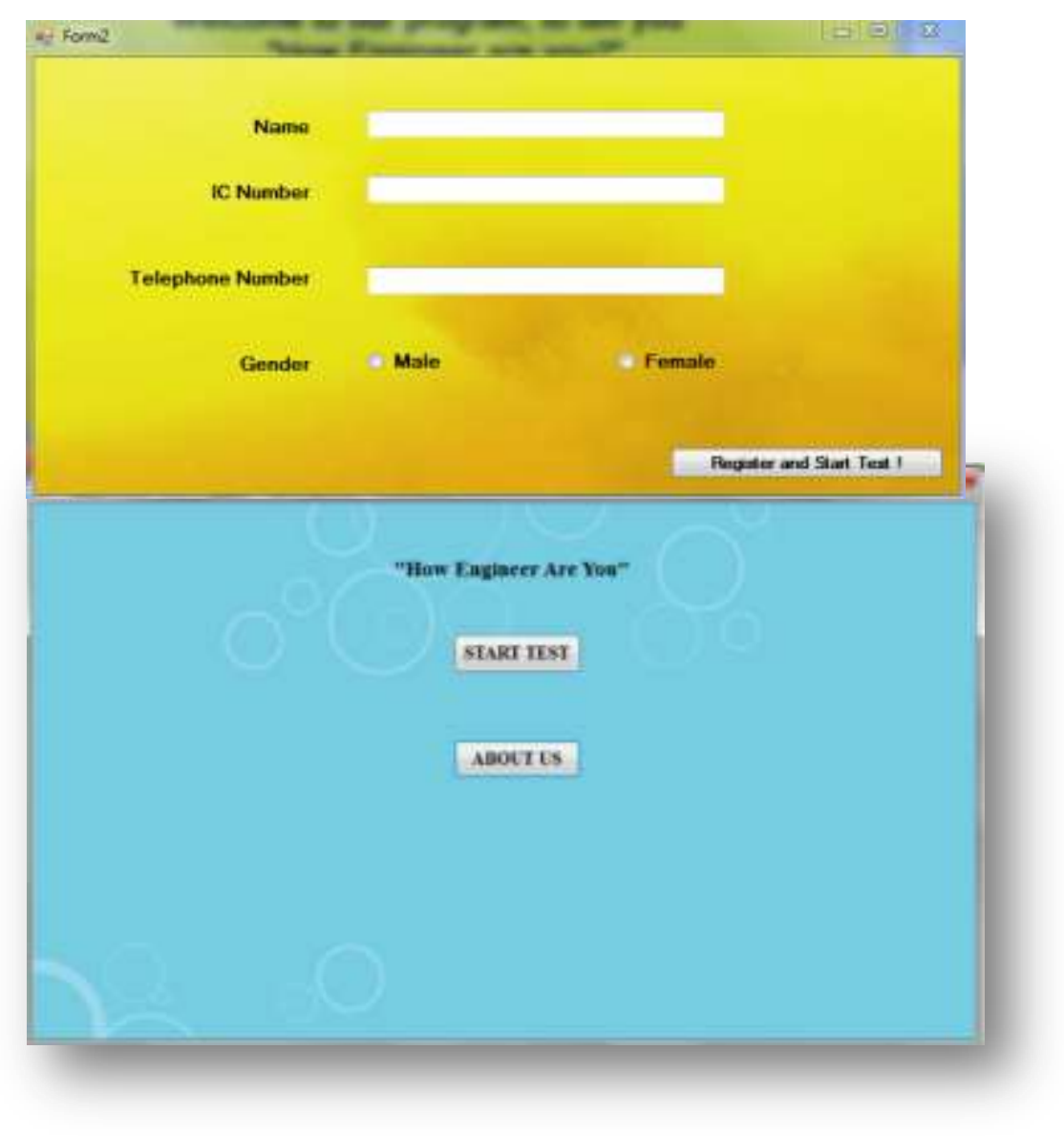

Fig.3: Simplified Main interface of the Software

The 'Personal Intelligence Test' (PIT) as per Fig.4 enables respondent and even potential employers determine the extent of 'engineering intelligence' one possesses. At this stage, respondent discovers own intelligence for pursuing the field of engineering or even redefining their career in terms of their habits. 


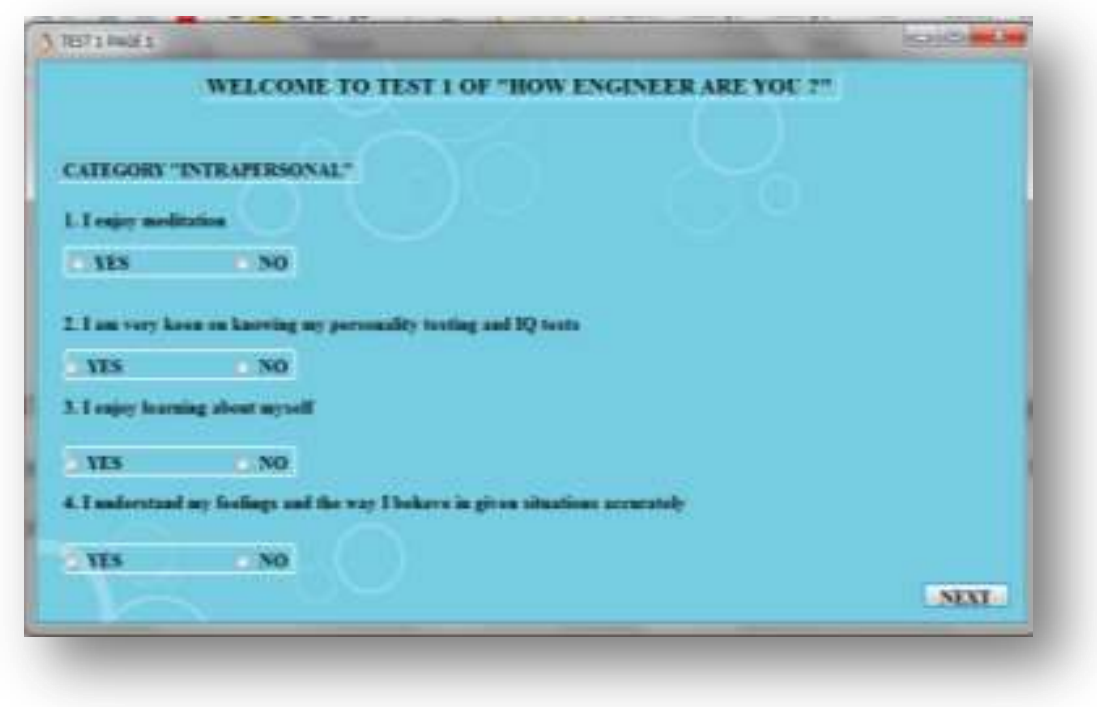

Fig.4: 'Personal Intelligence Test' (PIT)

This test (as per Figure 5) enables respondent and even potential employers determine the extent of 'engineering personality' one possesses. At this stage, respondent discovers own aptitude for pursuing the field of engineering or even redefining their career.

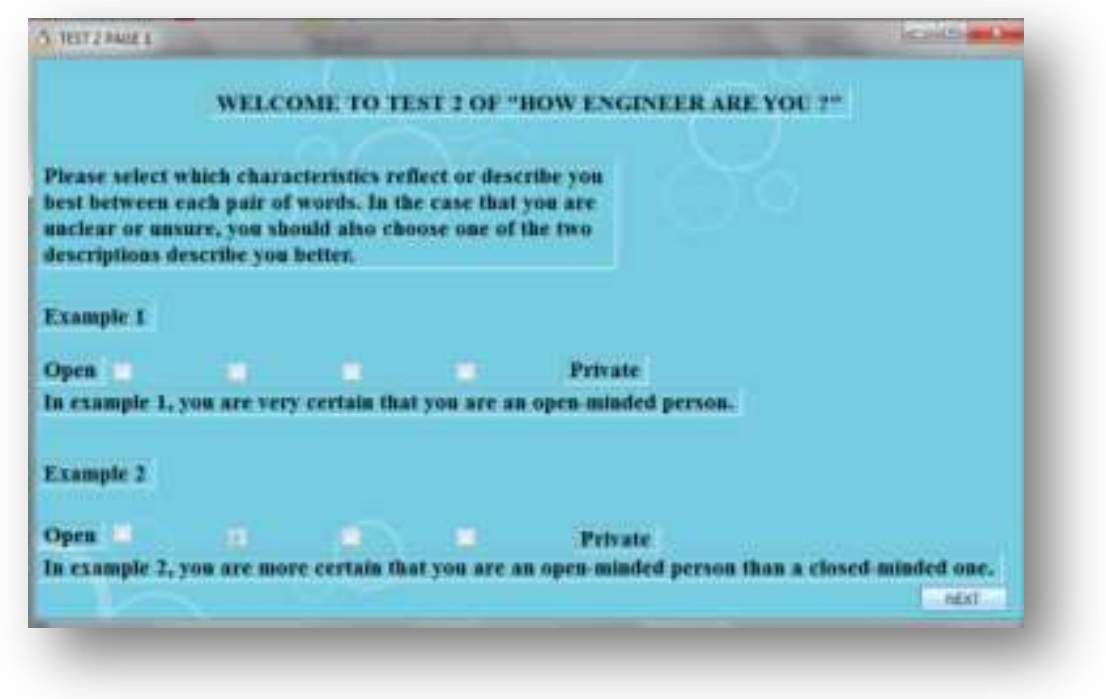

Fig. 5: 'Engineering Personality Test' (EPT)

The 'Engineering Vocabulary Test' (EVT) (Fig. 6) enables respondent and even potential employers determine the extent of 'engineering language' one possesses. At this stage, respondent discovers the extent of own engineering vocabulary (specialised vocabulary) to cope in the field of engineering. Alternatively, the employers or selection committee will find out how 'fluent' their candidate in using engineering language. 


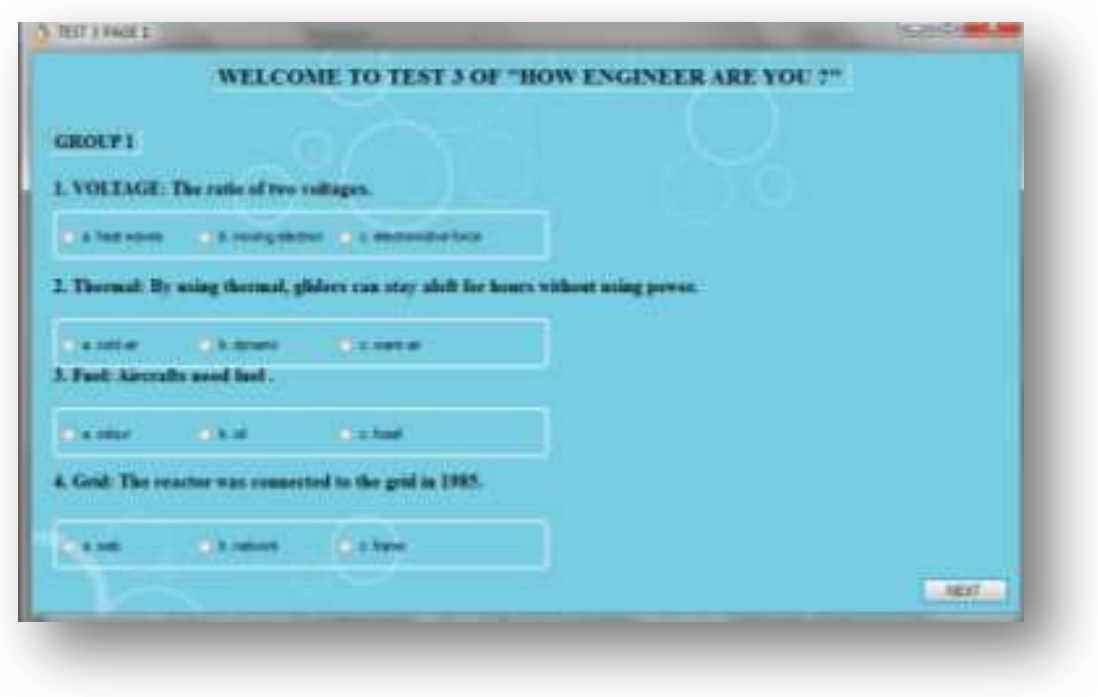

Fig.6: 'Engineering Vocabulary Test' (EVT)

\section{Conclusion}

This is the first of its kind of the prototype which serves the purposes discussed. It is important to match the respondents to the most relevant engineering job made available to them as well as assisting companies to select the most desirable talent in fulfilling the mission of the company. This software stores the data of the respondents with their respective digitized credentials and matches the need of the industry. Besides the three tests discussed, the software can also incorporate customized interview questions, access respondent's technical knowledge on physics and engineering subjects in order to find out whether they can perform and think in any given critical situation.

\section{References}

[1] Alif Fairus Nor Mohamad \& Ng, Y. J. (2013). Corpus-based studies on nursing textbooks. Advances in Language and Literary Studies, 4(2), 21-28. doi:10.7575/aiac.alls.v.4n.2p.21

http://dx.doi.org/10.7575/aiac.alls.v.4n.2p.21

[2] Bandura, A, Barbaranelli, C., Caprara, G.V. \& Pastorelli, C (2001). Self-efficacy beliefs as shapers of children's aspirations and career trajectories.. Child Development, 72, 187-206

http://dx.doi.org/10.1111/1467-8624.00273

[3] Coxhead, A. (2013). Vocabulary and ESP. In B. Paltridge \& S. Starfield (Eds.). The handbook of English for Specific Purposes (pp. 115 - 132). Sussex, UK: John Wiley and Sons Inc.

[4] Ferry, N.M. (2006). Factors influencing career choices of adolescents and young adults in rural Pennsylvania. Journal of Extension, 44 [Online]. Available: http://www.joe.org/joe/2006june/rb7.php

[5] Hsu, W. (2014). Measuring the vocabulary load of engineering textbooks for EFL undergraduates. English for Specific Purposes, 33 (1), 54-65. http://dx.doi.org/10.1016/j.esp.2013.07.001

[6] Jung, C.G. (1971). Psychological types (Collected works of C. G. Jung, volume 6 (2ed). Princeton, USA: Princeton University Press.

[7] Lieberman, D.J. (2010). If God Were Your Therapist: How To Love Yourself And Your Life, And Never Feel Angry, Anxious, Or Insecure Again. Lakeword, NJ: USA, Viter Press

[8] Ministry of Education Malaysia (2012). Preliminary report: Malaysian education blueprint 2013 - 2025. Available online at http://www.moe.gov.my/userfiles/file/PPP/Preliminary-Blueprint-Eng.pdf

[9] Mukundan, J. \& Ng, Y.J. (2012). Development of a technical nursing education word list (NEWL). International Journal of Innovation in English Language Teaching and Research, 1(2), 105-124. 
[10] Myers, I.B. \& Myers, P.B (1995). Gifts differing: Understanding personality type. London, UK: Nicholas Brealey Publishing

[11] Nation, I. S. P. (2006). How large a vocabulary is needed for reading and listening? The Canadian Modern Language Review, 63(1), 59-82. http://dx.doi.org/10.3138/cmlr.63.1.59

[12] Nation, I. S. P., \& Beglar, D. (2007). A vocabulary size test. The Language Teacher, 31(7), 9-13

[13] Nesi, H. (2013). ESP and corpus studies. In B. Paltridge \& S. Starfield (Eds.). The handbook of English for Specific Purposes (pp. 407 - 426). Sussex, UK: John Wiley and Sons Inc.

[14] Ng, Y. J., Lee, Y.L., Chong, S.T. Nurhanis Sahiddan, Philip, A. Noor Hafiza Nor Azmi \& Mohd Ariff Ahmad Tarmizi. (2013). Development of the engineering technology word list for vocational schools in Malaysia. International Education Research, 1(1), 43-59. http://dx.doi.org/10.12735/ier.v1i1p43

[15] Thoresen, C. E., Kirmil-Gray, K. \& Crosbie, M (1978). Processes and procedures of self-control. Canadian Couns 12, $66-75,1978$.

[16] Thoresen, C.E. \& Ewart, C.K. (1976). Behavioural Self-Control and Career Development. The Counselling Psychologist, 6,29-43. http://dx.doi.org/10.1177/001100007600600307 